\title{
Evaluation of a community intervention program in Japan using Framingham risk score and estimated 10-year coronary heart disease risk as outcome variables: a non-randomized controlled trial
}

Bing Zhu ${ }^{1,3}$, Yasuo Haruyama ${ }^{1 *}$, Takashi Muto ${ }^{1}$, Akiko Yamasaki ${ }^{2}$ and Fumiko Tarumi²

\begin{abstract}
Background: Community-based programs are being widely adopted in the struggle to prevent cardiovascular diseases. No study has been conducted in Japan to evaluate the effects of a community-based health promotion program by using the Framingham risk score and 10-year CHD risk as outcome variables. The aim of the present study was to assess the effects of a program involving 6-month intervention and 18-month follow-up using such outcomes.
\end{abstract}

Methods: Participants ( $n=1,983,39.5 \%$ women, mean age 63.4 years) were selected for the study in 2008. Of these 1,983, 347 (42.4\% women) subjects received the 6-month intervention. The intervention included individual counseling and group sessions, among others. After 18 months, 1,278 participants (intervention group: 238, control group: 1,040) were followed up. Changes in the Framingham risk score and 10-year coronary heart disease (CHD) risk were evaluated. ANCOVA and multiple logistic models adjusted for baseline value, age, sex and intervention times were used.

Results: The results showed that the differences in the Framingham risk score and mean 10-year CHD risk were significant in the intervention group compared with the control group after 6-month follow-up (-0.46 and -1.12, respectively) and were also significant after 18-month follow-up ( -0.39 and -0.85 , respectively). The proportion of those with intermediate 10-year CHD risk (> =10\%) was significantly lower at 6 months (OR 0.30, 95\% Cl 0.12-0.74) and at 18 months (OR 0.41, 95\% Cl 0.19-0.92).

Conclusions: The six-month intervention program effectively decreased estimated 10-year CHD risk and the effects were still present at 18-month follow-up.

Trial registration: UMIN-CTR: UMIN000008163

Keywords: Coronary disease, Lifestyle, Prevention, Risk factors

\footnotetext{
* Correspondence: yasuo-h@dokkyomed.ac.jp

'Department of Public Health, Dokkyo Medical University School of Medicine,

Tochigi, Japan

Full list of author information is available at the end of the article
} 


\section{Background}

Morbidity and mortality due to cardiovascular disease are now the leading public health problems in industrialized countries, including Japan $[1,2]$. Heart disease is the second leading cause of mortality in Japan [2].

Community-based programs are being widely adopted in the struggle to prevent cardiovascular diseases. Community approaches to cardiovascular disease (CVD) prevention are attractive, since they can target all groups in the community and, if effective, may achieve widespread behavioral change and risk reduction. A number of community CVD prevention programs have been implemented over the last 40 years [3].

As the incidence of cardiovascular disease is largely explained by modifiable risk factors (serum cholesterol and reduced high-density-lipoprotein cholesterol, blood pressure and cigarette smoking), reducing risk factors through health promotion focusing on lifestyle is a logical way of preventing disease [4].

In the meantime, as evidence-based health promotion is becoming more and more important, outcome evaluation variables are needed by experts to evaluate the effect of health promotion programs. Since it is not appropriate to trace the incidence of cardiovascular disease for an intervention study, estimation equations to evaluate the incidence rate have been widely adopted. The Framingham risk score used to evaluate 10-year coronary heart disease (CHD) risk is the most popular estimation equation, which was derived from the Framingham Heart Study [5-8]. Many intervention studies implemented in Western countries have used the Framingham risk score to evaluate the effect of intervention studies [9-15].

In Asia, although there has been some controversy over whether the Framingham risk score overestimates the risk of CHD in Asian populations [16,17], it is still used by experts to provide useful information on future CHD events $[18,19]$.

To our knowledge, this study is the first to use the Framingham risk score and 10-year CHD risk to evaluate the effects of a community-based health promotion program in Japan.

The hypothesis in this study was that, similar to studies conducted in Western countries, lifestyle interventions could reduce the Framingham risk score and estimated 10-year CHD risk after 18-month follow-up relative to a control group.

The aim of the present study was to assess the effect of a program involving six-month intervention and 18-month follow-up in a Japanese community using Framingham risk score and 10-year CHD risk as outcome variables.

\section{Methods}

\section{Study design}

The Ministry of Health, Labour and Welfare (MHLW) in Japan started the "Specific Health Check-up Project" nationally in 2008. This study was one part of the project, which was implemented in Soka City in Saitama Prefecture, Japan, with a population of about 233,000 $[20,21]$.

The present study employed a non-randomized controlled trial design. The program was provided from 2008 to 2010, including a 6-month intervention program and an 18-month follow-up program.

\section{Participants}

About 50,000 residents aged from 40-74 were invited to receive a health check-up. As shown in Figure 1, 12,961 residents aged 40-75 years old underwent health checkups in 2008 and completed the baseline lifestyle questionnaire. Of these 12,961 subjects, 1,983 were selected for the study according to the following inclusion criteria [22], which were separated into two steps: (1) waist circumferences of the subjects as follows: (1)waist circumference $>=85 \mathrm{~cm}$ for males, $>=90 \mathrm{~cm}$ for females; (2)waist circumference $<85 \mathrm{~cm}$ for males, $<90 \mathrm{~cm}$ for females, and body mass index (BMI) $>=25 \mathrm{~kg} / \mathrm{m}^{2}$; (2) at least one of the following: hemoglobin (HbA1c) $>5.2 \%$ (JDS, Japan Diabetes Society) (equal to $>5.6 \%$ [NGSP, National Glycohemoglobin Standardization Program]) [23] or taking diabetes medication; triglycerides (TG) $>150 \mathrm{mg} / \mathrm{dl}$ or high-density-lipoprotein cholesterol $(\mathrm{HDL}-\mathrm{C})<40 \mathrm{mg} / \mathrm{dl}$ or taking lipid-lowering medication; systolic blood pressure (SBP) $>=130 \mathrm{mmHg}$ or diastolic blood pressure $(\mathrm{DBP})>=85 \mathrm{mmHg}$ or taking hypertension medication; and having a history of smoking. The subjects who were taking diabetes, lipid-lowering and hypertension medication and were diagnosed as hypertension $(\mathrm{SBP} / \mathrm{DBP}>=140 / 90 \mathrm{mmHg}$ ), hyperlipidemia $(\mathrm{LDL}>=140 \mathrm{mg} / \mathrm{dl}$ or $\mathrm{HDL}<40 \mathrm{mg} / \mathrm{dl}$ or $\mathrm{TG}>=$ $150 \mathrm{mg} / \mathrm{dl}$ ), diabetes (Fasting blood glucose $>=126 \mathrm{mg} /$ $\mathrm{dl}$ or $\mathrm{HbA} 1 \mathrm{c}>=6.1 \%$ (JDS) (equal to $>=6.5 \%$ [NGSP])) were advised to be seen by physicians, and were withdrawn from this study. The 1,983 subjects were informed about the program by direct mail and were then allocated into either the intervention or the control group according to the participants' desire. The numbers of subjects in the intervention and control groups were 347(200 males and 147 females) and 1,636 (999 males and 637 females), respectively. After 6-month follow-up, 1,288 (251 in the intervention group and 1,037 in the control group) participants underwent the second health check-up and completed the lifestyle questionnaire. Finally, after the 18-month follow-up, 1,278 participants (238 in the intervention group and 1,040 in the control 


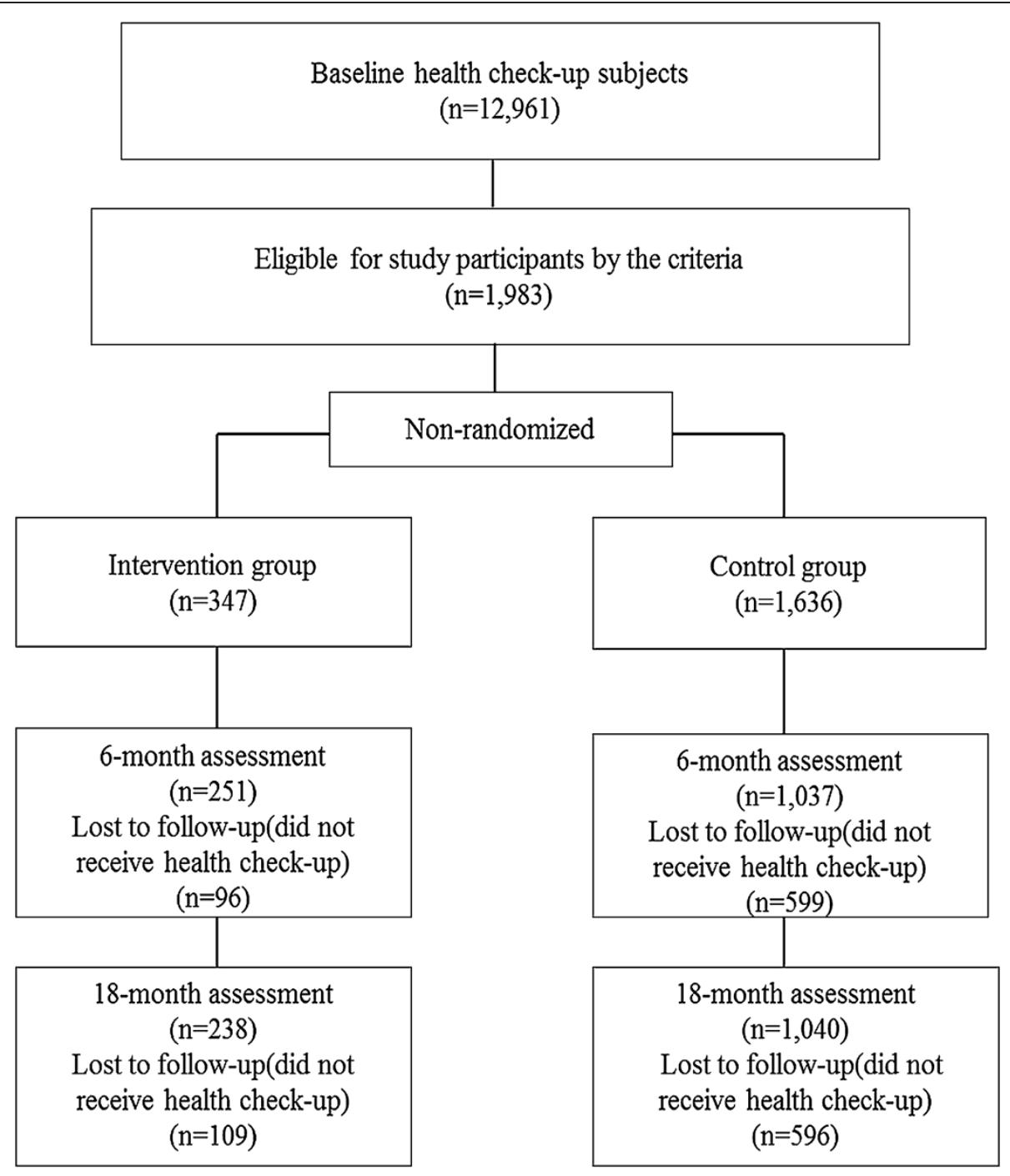

Figure 1 Flowchart of the study protocol.

group) completed the final health check-up and lifestyle questionnaire in 2010 (Figure 1).

\section{Risk factor measurements}

All of the measurements were provided by medical institutions. Body weight and height were measured with no shoes and excess clothing removed on the same calibrated scale at the baseline, 6-month and 18-month follow-up. BMI was calculated as body weight $(\mathrm{kg}) \mathrm{di}-$ vided by the square of the height $\left(\mathrm{m}^{2}\right)$. Waist circumference was measured by nurses. SBP and DBP were measured using auto-manometers (Omron Co., Tokyo, Japan). Fasting blood samples from all subjects were obtained and TG, low-density lipoprotein cholesterol (LDL-C), HDL-C and HbA1c were measured at a laboratory (Saitama, Japan).
Subjects with overweight were defined as having a BMI > $=25 \mathrm{~kg} / \mathrm{m}^{2}$; subjects with hypertension risk were defined as having at least one of the following: $\mathrm{SBP}>=$ $130 \mathrm{mmHg}$ or $\mathrm{DBP}>=85 \mathrm{mmHg}$; subjects with dyslipidemia risk were defined as having at least one of the following: HDL-C $<40 \mathrm{mg} / \mathrm{dl}$, LDL-C $>=140 \mathrm{mg} / \mathrm{dl}$ or $\mathrm{TG}>=150 \mathrm{mg} / \mathrm{dl}$; subjects with diabetes risk were defined as having a HbA1c $>5.2 \%$ (JDS) (equal to $>5.6 \%$ [NGSP]).

We used the Framingham risk score, which is based on age, TC, HDL-C, SBP and current smoking status, in order to establish risk scores [8]. HDL-C was classified into 4 levels $(>=60,50-59,40-49,<40 \mathrm{mg} / \mathrm{dl})$. SBP was classified into 5 levels $(<120,120-129,130-139,140-159,>=$ $160 \mathrm{mmHg}$ ). TC was calculated according to the Friedewald equation [24]. Estimated 10-year CHD risk was evaluated according to the Framingham risk score 
[8]. Moreover, we also used intermediate 10-year CHD risk with a definition of $>=10 \%[8]$.

\section{Assessment of lifestyle variables}

Information on lifestyle factors such as smoking, drinking alcohol, dietary behaviors and physical activity, medical history and sleeping was obtained by a self-administered questionnaire at the baseline, 6 and 18 months.

Current smokers were defined as those who had been smoking for 6 months or had smoked over 100 cigarettes and were still smoking in the previous month. Drinking alcohol was indicated by the frequency of drinking and the amount of alcohol consumption per day. Dietary behaviors included eating speed, usual time for eating supper, eating snacks and skipping breakfast. Physical activity included regular exercise, daily physical activity and walking speed. Sleeping status was categorized as well or not well.

In this study, the preferable lifestyle behaviors were defined as follows: no smoking, exercise over 30 minutes and 2 times per week, walking or having physical activity over 1 hour every day, walking faster than their peers, not eating fast, not eating dinner less than 2 hours before sleeping, not eating snacks over 3 times every week, not skipping breakfast over 3 times every week, not drinking alcohol every day, drinking alcohol less than $22 \mathrm{~g}$ and sleeping well.

\section{Intervention}

All subjects in the intervention and control groups were given 3 health checkups and 3 lifestyle surveys at the baseline, 6-month follow-up, and 18-month follow-up.

The common program consisted of a lecture regarding the purpose of health promotion at the baseline and newsletters featuring general health information provided by local community health workers during the 18 month period.

For the intervention group, a comprehensive program consisting of a 6-month intervention was provided. The 6-month intervention program included individual counseling and group sessions, in addition to the common program.

\section{Individual counseling}

Individual counseling was conducted on the basis of the results of health check-ups and health assessment charts on lifestyle at the baseline (60 minutes per person).

\section{Group sessions}

The group sessions focused on nutrition and exercise (a total of 12 times of $60-120$ minutes duration). The nutrition group sessions included talks, a lecture, cooking demonstrations and motivational interviewing. The exercise group sessions included aerobic exercises, stretching, walking and other exercises in a gym or local health or community center. The same program was provided during the daytime and at night for the convenience of participants. Through these approaches, participants were encouraged to set their own goals for lifestyle modification.

\section{Other interventions by telephone and letter}

The other interventions included contact by telephone (a total of 3 times of 5-15 minutes duration) and letter (a total of 3 times). Through telephone calls and letters, subjects were advised to attend the group sessions and motivated to change their lifestyle behaviors. Those who were absent from the group sessions were also followed up by telephone or letter to inquire about the reason. The changes in lifestyle behaviors among the subjects were also evaluated by questions over the telephone.

\section{Statistical analysis}

We selected lifestyle behaviors and cardiovascular disease risks as outcome measures in this study. Lifestyle behaviors included smoking, dietary behaviors, physical activity, drinking alcohol and sleeping. Cardiovascular disease risks included weight, BMI, waist circumference, SBP, DBP, HDL-C, LDL-C, TG and HbA1c.

Baseline cardiovascular disease risk and lifestyle behavior differences were analyzed by Student's t-test for continuous variables, Mann-Whitney test for nonparametric variables and Chi-squared test for categorical variables.

The mean differences in changes in cardiovascular disease risk factors at 6 and 18 months between the intervention and control groups were assessed by covariance analysis adjusted for the baseline value, age, sex and intervention times. Comparisons of lifestyle behaviors at 6 and 18 months between the intervention and control groups were conducted by multiple logistic regression analysis adjusted for the baseline category, age and sex. The odds ratios (OR) and 95\% confidence interval $(95 \% \mathrm{CI})$ were used to indicate the relative risk ratio between the intervention and control groups. In addition, we determined the probability of risk in subjects with overweight, hypertension risk, dyslipidemia risk, diabetes risk, metabolic syndrome and 10-year CHD risk by multiple logistic regression analysis adjusted for the baseline category, age, sex and intervention times. All statistical analyses were performed using an assumed type I error rate of 0.05. Statistical analyses were performed using SPSS Statistics 20.0 for Windows (SPSS Japan Inc., Tokyo, Japan). 


\section{Ethical consideration}

Ethical approval was given by the ethics committee at Dokkyo Medical University (No2057).

\section{Results}

\section{Baseline characteristics of participants}

The baseline characteristics of the study participants are presented in Table 1. The mean age in the intervention group was significantly higher than that in the control group $(\mathrm{P}<0.001)$. In addition, the baseline characteristics of the completed and drop-out subjects in the intervention group were compared (not shown in Table). In
2009 , the mean age in the drop-out group was younger than that in the completed group $(\mathrm{P}=0.006)$. In 2010, weight and mean 10-year CHD risk were higher and HDL-C was lower in the drop-out group than in the completed group $(\mathrm{P}=0.012,0.018$ and 0.011 respectively). Other variables including the Framingham risk score showed no significant differences between the two groups.

The proportions of those with current smoking $(\mathrm{P}=0.023)$, eating dinner late $(\mathrm{P}=0.009)$ and skipping breakfast $(\mathrm{P}<0.001)$ were significantly lower in the intervention group than those in the control group. The

Table 1 Characteristics of baseline cardiovascular disease risks and lifestyle behaviors between intervention and control groups

\begin{tabular}{|c|c|c|c|}
\hline & Intervention N = 347 & Control $\mathrm{N}=1,636$ & P-value $^{\mathrm{a}}$ \\
\hline & Mean \pm S.D. & Mean \pm S.D. & \\
\hline Age, year & $65.0 \pm 7.8$ & $63.0 \pm 8.8$ & $<0.001$ \\
\hline Weight, kg & $66.1 \pm 8.1$ & $66.8 \pm 9.2$ & 0.166 \\
\hline $\mathrm{BMI}, \mathrm{kg} / \mathrm{m}^{2}$ & $25.8 \pm 2.3$ & $25.8 \pm 2.4$ & 0.960 \\
\hline Waist, $\mathrm{cm}$ & $91.0 \pm 5.8$ & $90.9 \pm 6.2$ & 0.942 \\
\hline $\mathrm{SBP}, \mathrm{mmHg}$ & $134.0 \pm 14.6$ & $135.5 \pm 16.6$ & 0.121 \\
\hline $\mathrm{DBP}, \mathrm{mmHg}$ & $79.7 \pm 9.7$ & $80.8 \pm 10.5$ & 0.077 \\
\hline $\mathrm{HDL}-\mathrm{C}, \mathrm{mg} / \mathrm{dl}$ & $57.3 \pm 14.5$ & $56.2 \pm 14.9$ & 0.179 \\
\hline $\mathrm{LDL}-\mathrm{C}, \mathrm{mg} / \mathrm{dl}$ & $134.0 \pm 29.6$ & $133.8 \pm 32.1$ & 0.933 \\
\hline $\mathrm{TG}, \mathrm{mg} / \mathrm{dl}$ & $151.1 \pm 95.8$ & $165.8 \pm 130.7$ & $0.287^{\mathrm{b}}$ \\
\hline $\mathrm{HbA}_{1 c} \%$ & $5.34 \pm 0.47$ & $5.38 \pm 0.82$ & 0.395 \\
\hline Framingham risk score, score & $14.0 \pm 2.5$ & $13.7 \pm 2.9$ & 0.085 \\
\hline \multirow[t]{2}{*}{ Mean 10-year CHD risk,\% } & $9.3 \pm 6.0$ & $9.4 \pm 6.4$ & 0.646 \\
\hline & $N(\%)$ & $N(\%)$ & \\
\hline \multicolumn{4}{|l|}{ Sex } \\
\hline male & $200(57.6)$ & $999(61.1)$ & 0.236 \\
\hline female & $147(42.4)$ & $637(38.9)$ & \\
\hline Current smoker & $62(17.9)$ & $384(23.5)$ & 0.023 \\
\hline \multicolumn{4}{|l|}{ Physical activity } \\
\hline Exercise over than $30 \mathrm{~min},>=2$ times/week & $159(51.6)$ & $595(39.7)$ & $<0.001$ \\
\hline Walking or physical activity over than 1 hour every day & $168(54.9)$ & $707(47.3)$ & 0.015 \\
\hline Walking faster than their peers & $171(55.9)$ & $771(52.1)$ & 0.231 \\
\hline \multicolumn{4}{|l|}{ Dietary behavior } \\
\hline Eating fast & $88(28.5)$ & $410(27.4)$ & 0.686 \\
\hline Eating dinner less than 2 hours before sleeping & $62(20.1)$ & $406(27.2)$ & 0.009 \\
\hline Eating snacks over than 3 times every week & $42(13.6)$ & $200(13.4)$ & 0.900 \\
\hline Skipping breakfast over than 3 times every week & $22(7.1)$ & $218(14.6)$ & $<0.001$ \\
\hline Drinking alcohol every day & $156(50.5)$ & $669(44.7)$ & 0.063 \\
\hline Drinking alcohol less than $22 \mathrm{~g}$ & $143(60.9)$ & $666(56.8)$ & 0.249 \\
\hline Sleeping well & $247(81.0)$ & $1148(77.2)$ & 0.147 \\
\hline
\end{tabular}

$\mathrm{BMI}=$ body mass index, waist $=$ waist circumference, $\mathrm{SBP}=$ systolic blood pressure, $\mathrm{DBP}=$ diastolic blood pressure, $\mathrm{HDL}-\mathrm{C}=$ high-density lipoprotein cholesterol, $\mathrm{LDL}-\mathrm{C}=$ low-density lipoprotein cholesterol, TG = Triglycerides, HbA1c = Hemoglobin, CHD = coronary heart disease.

aby chi-squared or Student's t-test.

by Mann-Whitney test. 
proportions of those with regular exercise $(\mathrm{P}<0.001)$ and daily physical activity $(\mathrm{P}=0.015)$ were significantly higher in the intervention group than those in the control group. There were no other significant differences in baseline characteristics between the two groups.

The number of interventions in the intervention group was an average of 7.1 (range from1 to15) (not show in Table).

\section{Changes in lifestyle behaviors}

Table 2 shows the odds ratios of preferable lifestyle behaviors in the intervention group versus the control group. Multiple logistic regression analysis adjusted for each baseline category, age and sex showed that the proportion of those performing regular exercise was significantly higher in the intervention group than in the control group at 6 months (OR 1.79, 95\% CI 1.24-2.59). The proportion of those who walked or did physical activity over 1 hour every day was significantly higher in the intervention group than in the control group at 6 months (OR 1.51, 95\% CI 1.06-2.14). The proportion of those who walked faster than their peers was significantly higher in the intervention group than in the control group at 6 months (OR 1.45, 95\% CI 1.01-2.09). The proportion of those who ate snacks over than 3 times every week was significantly lower in the intervention group than in the control group at 6 months (OR 0.35, 95\% CI 0.17-0.71) and it was still lower at 18 months (OR 0.48, 95\% CI 0.23-0.98). There were no other significant differences in lifestyle behaviors between the two groups. Moreover, in 2009, 37 people (6 in the intervention group and 31 in the control group) stopped smoking after 6-month follow-up, which accounted for $2.9 \%$; in 2010, 58 people (9 in the intervention group and 49 in the control group) stopped smoking after 18month follow-up, which accounted for $4.5 \%$.

\section{Changes in cardiovascular disease risks}

Baseline to 6-month changes in cardiovascular disease risks between the two groups are displayed in Table 3. Presented below and in the tables are the unadjusted means and adjusted $\mathrm{P}$ values by using covariance analysis controlling for age, sex, baseline values and intervention times.

The mean decreases in weight $(\mathrm{P}=0.002)$ and BMI $(P=0.004)$ in the intervention group showed significant differences compared with those in the control group. The average Framingham risk score in the intervention group showed a significant decrease $(P=0.002)$. The mean 10-year CHD risk also showed a significant decrease in the intervention group $(\mathrm{P}=0.001)$.

HDL-C and LDL-C in the intervention group showed slight increases compared with those in the control group, but the increases were not statistically significant. All other cardiovascular disease risks showed a decrease in the intervention group, but the reductions were not statistically significant.

The changes in cardiovascular disease risks between the two groups at 18 months are shown in Table 4 . Covariance analysis adjusted for baseline values, age, sex and intervention times showed that the average weight $(\mathrm{P}=0.003)$, BMI $(\mathrm{P}=0.007)$, waist circumference $(\mathrm{P}=0.039)$ and TG $(\mathrm{P}=0.021)$ in the intervention group were significantly decreased at 18 months. The Framingham risk score $(\mathrm{P}=0.022)$ and mean 10 -year $\mathrm{CHD}$ risk $(P=0.027)$ were significantly decreased in the intervention group compared with those in the control group. DBP, HDL-C and LDL-C in the intervention group

Table 2 Comparison of changes in lifestyle behavior between intervention and control groups

\begin{tabular}{|c|c|c|c|c|}
\hline & \multicolumn{2}{|c|}{ At 6 months 251 vs. 1,037} & \multicolumn{2}{|c|}{ At 18 months 238 vs. 1,040} \\
\hline & $\mathrm{OR}^{\mathrm{a}}$ & $95 \% \mathrm{Cl}$ & $\mathrm{OR}^{\mathrm{a}}$ & $95 \% \mathrm{Cl}$ \\
\hline Current smoker & 0.83 & $0.37-1.87$ & 0.62 & $0.30-1.28$ \\
\hline \multicolumn{5}{|l|}{ Physical activity } \\
\hline Exercise over $30 \mathrm{~min},>=2$ times/week & 1.79 & $1.24-2.59$ & 1.27 & $0.90-1.80$ \\
\hline Walking or physical activity over than 1 hour every day & 1.51 & $1.06-2.14$ & 1.30 & 0.93-1.82 \\
\hline Walking faster than their peers & 1.45 & $1.01-2.09$ & 1.06 & $0.74-1.52$ \\
\hline \multicolumn{5}{|l|}{ Dietary behavior } \\
\hline Eating fast & 1.45 & $0.91-2.30$ & 0.98 & $0.61-1.57$ \\
\hline Eating dinner less than 2 hours before sleeping & 0.82 & $0.52-1.29$ & 0.68 & 0.43-1.09 \\
\hline Eating snacks over than 3 times every week & 0.35 & $0.17-0.71$ & 0.48 & $0.23-0.98$ \\
\hline Skipping breakfast over than 3 times every week & 0.45 & $0.18-1.09$ & 0.42 & $0.16-1.15$ \\
\hline Drinking alcohol every day & 0.78 & $0.42-1.45$ & 1.23 & $0.78-1.94$ \\
\hline Drinking alcohol less than $22 \mathrm{~g}$ & 1.57 & $0.92-2.68$ & 1.28 & $0.77-2.15$ \\
\hline Sleeping well & 1.01 & $0.65-1.56$ & 0.88 & $0.57-1.35$ \\
\hline
\end{tabular}

aby multiple logistic regression analysis adjusted for baseline category, age and sex. 
Table 3 Comparison of changes in cardiovascular disease risk between intervention and control groups at 6-month follow-up

\begin{tabular}{|c|c|c|c|c|c|c|}
\hline & & \multirow{2}{*}{$\mathbf{N}$} & \multirow{2}{*}{$\begin{array}{c}\text { Baseline } \\
\text { Mean } \pm \text { S.D. }\end{array}$} & \multirow{2}{*}{$\begin{array}{c}\text { 6-month } \\
\text { Mean } \pm \text { S.D. }\end{array}$} & \multicolumn{2}{|c|}{ Intervention vs. Control } \\
\hline & & & & & Difference & P-value \\
\hline \multirow{2}{*}{ Weight, kg } & Intervention & 251 & $65.6 \pm 8.0$ & $63.7 \pm 8.2$ & -0.93 & 0.002 \\
\hline & Control & 1037 & $65.7 \pm 8.3$ & $65.2 \pm 8.6$ & & \\
\hline \multirow{2}{*}{$\mathrm{BMl}, \mathrm{kg} / \mathrm{m}^{2}$} & Intervention & 251 & $25.8 \pm 2.2$ & $25.1 \pm 2.3$ & -0.37 & 0.004 \\
\hline & Control & 1037 & $25.6 \pm 2.2$ & $25.4 \pm 2.4$ & & \\
\hline \multirow{2}{*}{ Waist, $\mathrm{cm}$} & Intervention & 250 & $90.9 \pm 5.9$ & $88.5 \pm 6.6$ & -0.77 & 0.129 \\
\hline & Control & 1036 & $90.3 \pm 5.6$ & $89.6 \pm 6.3$ & & \\
\hline \multirow{2}{*}{$\mathrm{SBP}, \mathrm{mmHg}$} & Intervention & 251 & $133.7 \pm 14.0$ & $130.8 \pm 13.0$ & -1.77 & 0.212 \\
\hline & Control & 1037 & $134.8 \pm 15.5$ & $133.0 \pm 15.0$ & & \\
\hline \multirow{2}{*}{$\mathrm{DBP}, \mathrm{mmHg}$} & Intervention & 251 & $80.0 \pm 9.4$ & $77.4 \pm 8.7$ & -1.54 & 0.092 \\
\hline & Control & 1036 & $80.4 \pm 10.3$ & $79.3 \pm 9.7$ & & \\
\hline \multirow{2}{*}{$\mathrm{HDL}-\mathrm{C}, \mathrm{mg} / \mathrm{dl}$} & Intervention & 251 & $57.9 \pm 15.2$ & $58.5 \pm 15.1$ & 0.91 & 0.267 \\
\hline & Control & 1037 & $56.8 \pm 15.1$ & $56.6 \pm 15.3$ & & \\
\hline \multirow{2}{*}{$\mathrm{LDL}-\mathrm{C}, \mathrm{mg} / \mathrm{dl}$} & Intervention & 250 & $134.7 \pm 30.1$ & $130 . \pm 30.3$ & 2.78 & 0.227 \\
\hline & Control & 1036 & $131.9 \pm 30.9$ & $129.4 \pm 29.7$ & & \\
\hline \multirow{2}{*}{$\mathrm{TG}, \mathrm{mg} / \mathrm{dl}$} & Intervention & 251 & $141.1 \pm 65.8$ & $130.8 \pm 71.0$ & -14.9 & 0.150 \\
\hline & Control & 1036 & $158.8 \pm 125.9$ & $148.2 \pm 114.3$ & & \\
\hline \multirow{2}{*}{$\mathrm{HbA}_{1 c,} \%$} & Intervention & 251 & $5.33 \pm 0.43$ & $5.25 \pm 0.38$ & -0.05 & 0.179 \\
\hline & Control & 1033 & $5.33 \pm 0.62$ & $5.33 \pm 0.57$ & & \\
\hline \multirow{2}{*}{ Framingham risk score, score } & Intervention & 250 & $14.0 \pm 2.4$ & $13.9 \pm 2.4$ & -0.46 & 0.002 \\
\hline & Control & 1029 & $13.9 \pm 2.7$ & $13.9 \pm 2.9$ & & \\
\hline \multirow{2}{*}{ Mean 10-year CHD risk, \% } & Intervention & 250 & $9.1 \pm 5.9$ & $8.9 \pm 6.0$ & -1.12 & 0.001 \\
\hline & Control & 1030 & $9.4 \pm 6.2$ & $9.6 \pm 6.5$ & & \\
\hline
\end{tabular}

$\mathrm{BMI}=$ body mass index, waist $=$ waist circumference, $\mathrm{SBP}=$ systolic blood pressure, $\mathrm{DBP}=$ diastolic blood pressure, $\mathrm{HDL}-\mathrm{C}=\mathrm{high}$-density lipoprotein cholesterol, $\mathrm{LDL}-\mathrm{C}=$ low-density lipoprotein cholesterol, TG = Triglycerides, $\mathrm{HbA1c}=$ Hemoglobin, $\mathrm{CHD}=$ coronary heart disease.

${ }^{a}$ by covariance analysis adjusted for baseline values, age, sex and intervention times.

showed slight increases compared with those in the control group, but the increases were not statistically significant. All other cardiovascular disease risks showed a decrease in the intervention group, but the reductions were not statistically significant.

Table 5 shows the odds ratios of cardiovascular disease risks in the intervention group versus the control group. Multiple logistic regression analysis adjusted for each baseline category, age, sex and intervention times showed that the proportion of those with intermediate 10-year CHD risk $(>=10 \%)$ was significantly lower in the intervention group than in the control group at 6 months (OR $0.30,95 \%$ CI $0.12-0.74$ ) and at 18 months (OR 0.41, 95\% CI 0.19-0.92). The proportion of those with dyslipidemia risk was significantly lower in the intervention group than in the control group at 18 months (OR 0.59, 95\% CI 0.36-0.97).

\section{Discussion}

The major finding of the present study is a significant decrease in the mean 10-year CHD risk at 6-month follow-up and that the effects were still sustained at 18-month follow-up. The number of subjects with intermediate 10-year CHD risk $(>=10 \%)$ also decreased significantly at each follow-up time.

A previous study also showed significant change in 10-year CHD risk after lifestyle intervention. The results from the PREMIER Trial showed that, in individuals with prehypertension or stage 1 hypertension, 2 multicomponent behavioral interventions (EST + DASH and EST) significantly reduced the estimated 10 -year CHD risk by $12 \%$ and $14 \%$, respectively [9]. The DEPLOY pilot study indicated that communitybased delivery of the DPP lifestyle intervention could have a significant effect on prevention of CHD in overweight adults with abnormal glucose metabolism. At 4 and 12 months, the intervention group experienced significant decreases in 10-year risk from baseline $(-3.28 \%, \mathrm{P}<0.001$; and $-2.23 \%, \mathrm{P}=0.037)$ compared with control subjects $(-0.78 \%, \mathrm{P}=0.339$; and $+1.88 \%, \mathrm{P}=0.073$ ) [14]. The California WISEWOMAN Project reported that the improvement in 
Table 4 Comparison of changes in cardiovascular disease risk between intervention and control groups at 18-month follow-up

\begin{tabular}{|c|c|c|c|c|c|c|}
\hline & & \multirow{2}{*}{$\mathbf{N}$} & \multirow{2}{*}{$\begin{array}{c}\text { Baseline } \\
\text { Mean } \pm \text { S.D. }\end{array}$} & \multirow{2}{*}{$\begin{array}{l}\text { 18-month } \\
\text { Mean } \pm \text { S.D. }\end{array}$} & \multicolumn{2}{|c|}{ Intervention vs. Control } \\
\hline & & & & & Difference & P-value \\
\hline \multirow[t]{2}{*}{ Weight, kg } & Intervention & 238 & $65.4 \pm 7.9$ & $63.8 \pm 8.2$ & -1.08 & 0.003 \\
\hline & Control & 1040 & $66.0 \pm 8.7$ & $65.4 \pm 9.2$ & & \\
\hline \multirow[t]{2}{*}{$\mathrm{BMI}, \mathrm{kg} / \mathrm{m}^{2}$} & Intervention & 238 & $25.7 \pm 2.2$ & $25.1 \pm 2.3$ & -0.38 & 0.007 \\
\hline & Control & 1040 & $25.7 \pm 2.3$ & $25.5 \pm 2.6$ & & \\
\hline \multirow[t]{2}{*}{ Waist, cm } & Intervention & 238 & $90.8 \pm 5.7$ & $88.9 \pm 6.5$ & -1.13 & 0.039 \\
\hline & Control & 1040 & $90.6 \pm 5.9$ & $90.0 \pm 6.7$ & & \\
\hline \multirow[t]{2}{*}{$\mathrm{SBP}, \mathrm{mmHg}$} & Intervention & 238 & $133.9 \pm 14.5$ & $131.2 \pm 14.0$ & -0.91 & 0.520 \\
\hline & Control & 1040 & $135.2 \pm 16.1$ & $132.4 \pm 14.8$ & & \\
\hline \multirow[t]{2}{*}{$\mathrm{DBP}, \mathrm{mmHg}$} & Intervention & 238 & $79.6 \pm 9.6$ & $78.1 \pm 9.0$ & 0.27 & 0.778 \\
\hline & Control & 1040 & $80.7 \pm 10.5$ & $78.4 \pm 9.9$ & & \\
\hline \multirow[t]{2}{*}{$\mathrm{HDL}-\mathrm{C}, \mathrm{mg} / \mathrm{dl}$} & Intervention & 238 & $58.6 \pm 15.0$ & $58.6 \pm 14.8$ & 1.10 & 0.214 \\
\hline & Control & 1040 & $56.6 \pm 15.1$ & $56.3 \pm 15.3$ & & \\
\hline \multirow[t]{2}{*}{$\mathrm{LDL}-\mathrm{C}, \mathrm{mg} / \mathrm{dl}$} & Intervention & 238 & $134.2 \pm 29.1$ & $127.0 \pm 27.9$ & 0.59 & 0.823 \\
\hline & Control & 1040 & $133.9 \pm 31.5$ & $127.5 \pm 31.7$ & & \\
\hline \multirow[t]{2}{*}{$\mathrm{TG}, \mathrm{mg} / \mathrm{dl}$} & Intervention & 238 & $143.6 \pm 74.2$ & $136.5 \pm 76.2$ & -25.1 & 0.021 \\
\hline & Control & 1040 & $163.4 \pm 131.1$ & $156.7 \pm 119.4$ & & \\
\hline \multirow[t]{2}{*}{$\mathrm{HbA}_{1 c,} \%$} & Intervention & 238 & $5.32 \pm 0.39$ & $5.31 \pm 0.39$ & -0.03 & 0.429 \\
\hline & Control & 1040 & $5.35 \pm 0.66$ & $5.38 \pm 0.57$ & & \\
\hline \multirow[t]{2}{*}{ Framingham risk score, score } & Intervention & 238 & $13.9 \pm 2.4$ & $14.0 \pm 2.5$ & -0.39 & 0.022 \\
\hline & Control & 1040 & $13.9 \pm 2.7$ & $14.1 \pm 2.9$ & & \\
\hline \multirow[t]{2}{*}{ Mean 10-year CHD risk,\% } & Intervention & 238 & $8.7 \pm 5.8$ & $8.8 \pm 5.9$ & -0.85 & 0.027 \\
\hline & Control & 1040 & $9.3 \pm 6.4$ & $9.8 \pm 6.6$ & & \\
\hline
\end{tabular}

$\mathrm{BMI}=$ body mass index, waist = waist circumference, $\mathrm{SBP}=$ systolic blood pressure, $\mathrm{DBP}=$ diastolic blood pressure, $\mathrm{HDL}-\mathrm{C}=\mathrm{high}$-density lipoprotein cholesterol, $\mathrm{LDL}-\mathrm{C}=$ low-density lipoprotein cholesterol, TG = Triglycerides, HbA1c = Hemoglobin, CHD = coronary heart disease.

${ }^{a}$ by covariance analysis adjusted for baseline values, age, sex and intervention times.

the 10-year CHD risk was greater for an enhanced intervention group (EIG) than for a usual care group (UCG), and this improvement was significantly greater when the women's CHD risk levels were in the upper quartile at baseline [15].

From the results of our study, other cardiovascular disease risk factors did not show significant results, except for weight and BMI. This may have been caused by the 10-year CHD risk reflecting the comprehensive effect of intervention. Maybe some of the cardiovascular disease risk factors changed a little, but this was still not significant. When we combined the changes in cardiovascular disease risk factors together into the 10-year CHD risk, it showed a significant change.

The present study also showed the sustainment of the effect when the intervention was stopped after 18month follow-up. This proved that the effect of a short-

Table 5 Odds ratios of cardiovascular risks in intervention versus control group at each risk with baseline

\begin{tabular}{|c|c|c|c|c|}
\hline & \multicolumn{2}{|c|}{ At 6 months 251 vs. 1,037} & \multicolumn{2}{|c|}{ At 18 months 238 vs. 1,040} \\
\hline & $\mathrm{OR}^{\mathrm{a}}$ & $95 \% \mathrm{Cl}$ & $\mathrm{OR}^{\mathrm{a}}$ & $95 \% \mathrm{Cl}$ \\
\hline Overweight & 0.62 & $0.34-1.10$ & 0.56 & $0.31-1.01$ \\
\hline Hypertension risk & 1.06 & $0.66-1.70$ & 0.79 & $0.49-1.27$ \\
\hline Dyslipidemia risk & 0.75 & $0.45-1.24$ & 0.59 & $0.36-0.97$ \\
\hline Diabetes risk & 0.71 & $0.35-1.46$ & 0.65 & $0.32-1.29$ \\
\hline Intermediate 10 -year CHD risk (> = 10\%) & 0.30 & $0.12-0.74$ & 0.41 & $0.19-0.92$ \\
\hline
\end{tabular}


term intervention can be sustained after a long-term follow-up period, greater than one year.

Similar results were also shown in other previous studies. Lindstrom et al. found that lifestyle intervention in people at high risk for type 2 diabetes resulted in sustained lifestyle changes, a modest difference in body weight change and reduction in diabetes incidence, which remained after the individual lifestyle counseling stopped [25]. A study conducted by Elmer et al. showed that, over 18 months, persons with prehypertension and stage 1 hypertension could sustain multiple lifestyle modifications that improve control of blood pressure and could reduce the risk for chronic disease [26]. Fouryear results of the Look AHEAD Trial indicated that intensive lifestyle intervention can produce sustained weight loss and improvements in other CVD risk factors in individuals with type 2 diabetes [27].

The results of the present study indicated significant decrease in weight and body mass index at 6-month follow-up. In addition, the reductions were sustained and showed significantly stronger decrease at 18-month follow-up. This proved that, by implementing lifestyle intervention, weight loss can be achieved, which is similar to the results of previous studies.

In a lifestyle intervention study implemented among persons at high risk for cardiovascular disease and diabetes in a rural community, $52 \%$ of participants met the $7 \%$ weight loss goal and 66\% achieved at least a 5\% weight loss [28]. However, the sample size was very small $(\mathrm{N}=84$ and $\mathrm{N}=65$, respectively). A study conducted by Lindstrom et al. in 2003 indicated that, after 1 and 3 years, weight reductions were 4.5 and $3.5 \mathrm{~kg}$ in the intervention group and 1.0 and $0.9 \mathrm{~kg}$ in the control group, respectively [29]. In the present study, weight reduction was $1.5 \mathrm{~kg}$ in the intervention group and $0.6 \mathrm{~kg}$ in the control group after 18 months.

The present study has limitations. Firstly, our study has a non-randomized study design. The participants were allocated to either the intervention or the control group on the basis of each participant's desire. The subjects with a strong desire to improve their lifestyle were more inclined to accept the intervention and then acquired a better effect of changes in cardiovascular disease risk and lifestyle behavior. However, since the baseline cardiovascular disease risk factors were similar in the two groups, the non-randomized study design may not affect the main significant results in the changes of cardiovascular disease risk in our study.

Secondly, the assessment of lifestyle behavior change in the study was based on a self-reported questionnaire. This may have resulted in some recall bias when evaluating the change in lifestyle behavior and have led to little significant change in lifestyle behavior between the intervention and control groups. Further study should focus on a detailed method to evaluate the change in lifestyle behavior, such as using pedometers to measure change in physical activity.

Thirdly, this study has a high drop-out rate. On the one hand, as the results showed, younger people were more inclined to withdraw from our study, maybe because they were not interested in the form of the intervention. For example, younger people may prefer to choose more vigorous exercises instead of the jogging and gymnastics done in our study. On the other hand, subjects with higher BMI, thus having higher 10-year CHD risk, were more inclined to withdraw from our study, which limited the significance of the results.

Lastly, the number of participants was relatively small, especially in the intervention group, which might have limited the significance of the results and the generalization to the middle-aged Japanese population. Regarding the generalization of this study, the intensity of intervention that targeted a large percentage of the population who are at high risk of CVD may have been too strong. In a future study, a new method of intervention of less intensity should be developed, which can be applied worldwide, considering the limited ability of health services in many areas.

\section{Conclusions}

Our study demonstrates that the six-month intervention program effectively improved the cardiovascular disease risk and estimated 10-year CHD risk. Moreover, the effects were still present at the 18-month follow-up.

\section{Consent}

Written informed consent was obtained from the patient for publication of this report and any accompanying images.

\section{Competing interests}

The authors declare that they have no competing interests.

\section{Authors' contributions}

BZ coordinated data collection, carried out analysis and drafted the manuscript. YH conceived the study, participated in the study design, coordinated and participated in data collection and critically reviewed the manuscript. TM conceived the study, participated in the study design, and critically reviewed the manuscript. AY and FT conceived the study, were involved in the study design and participated in data collection. All authors read and approved the final manuscript.

\section{Acknowledgments}

The authors wish to thank the staff of Soka City Health Center and Soka City Office who worked on or cooperated with the present project, as well as the citizens of Soka City. This study was supported by grants from Soka City and supported in part by Japan China Sasakawa Medical Fellowship.

\section{Author details}

'Department of Public Health, Dokkyo Medical University School of Medicine, Tochigi, Japan. ${ }^{2}$ Soka City Health Center, Soka, Saitama, Japan. ${ }^{3}$ Division of Health Education, Anhui Provincial Center for Disease Control and

Prevention, Hefei, China. 
Received: 21 July 2012 Accepted: 6 March 2013

Published: 11 March 2013

\section{References}

1. WHO: World health statistics 2009. Geneva: World Health Organization; 2009.

2. Health, Labour and Welfare Statistics Association: Journal of health and welfare statistics. Tokyo: Kousaidoulnc; 2011. in Japanese.

3. Pennant M, Davenport C, Bayliss S, Greenheld W, Marshall T, Hyde C: Community Programs for the Prevention of Cardiovascular Disease: A Systematic Review. Am J Epidemiol 2010, 172:501-516.

4. Ebrahim S, Taylor F, Ward K, Beswick A, Burke M, Davey Smith G: Multiple risk factor interventions for primary prevention of coronary heart disease. Cochrane Database Syst Rev 2011:CD001561. http://onlinelibrary. wiley.com/doi/10.1002/14651858.CD001561.pub3/pdf.

5. Anderson KM, Odell PM, Wilson PW, Kannel WB: Cardiovascular disease risk profiles. Am Heart J 1991, 121:293-298.

6. Wilson PW, D'Agostino RB, Levy D, Belanger AM, Silbershatz H, Kannel WB: Prediction of coronary heart disease using risk factor categories. Circulation 1998, 97:1837-1847.

7. D'Agostino RB Sr, Vasan RS, Pencina MJ, Wolf PA, Cobain M, Massaro JM, Kannel WB: General cardiovascular risk profile for use in primary care: the Framingham Heart Study. Circulation 2008, 117:743-753.

8. Expert Panel on Detection, Evaluation, and Treatment of High Blood Cholesterol in Adults: Executive summary of the third report of the National Cholesterol Education Program (NCEP) Expert Panel on detection, evaluation, and treatment of high blood cholesterol in adults (adult treatment panel III). JAMA 2001, 285:2486-2497.

9. Maruthur NM, Wang N-Y, Appel L: Lifestyle interventions reduce coronary heart disease risk: results from the PREMIER trial. Circulation 2009, 119:2026-2031.

10. Wister A, Loewen N, Kennedy-Symonds H, McGowan B, McCoy B, Singer J: One-year follow-up of a therapeutic lifestyle intervention targeting cardiovascular disease risk. CMAJ 2007, 177:859-865.

11. Price $D$, Ramachandran $S$, Knight $T$, Jones PW, Neary RH: Observed changes in the lipid profile and calculated coronary risk in patients given dietary advice in primary care. Br J Gen Pract 2000, 50:712-715.

12. Ellsworth DL, O'Dowd SC, Salami B, Hochberg A, Vernalis MN, Marshall D, Morris JA, Somiari RI: Intensive lifestyle modification: impact on cardiovascular disease risk factors in subjects with and without clinical cardiovascular disease. Prev Cardiol 2004, 7:168-175.

13. Richardson G, van Woerden HC, Morgan L, Edwards R, Harries M, Hancock E, Sroczynsk S, Bowley M: Healthy Hearts-A community-based primary prevention programme to reduce coronary heart disease. BMC CardiovasC Disord 2008, 8:18.

14. Lipscomb ER, Finch EA, Brizendine E, Saha CK, Hays LM, Ackermann RT: Reduced 10-year risk of coronary heart disease in patients who participated in a community-based diabetes prevention program: the DEPLOY pilot study. Diabetes Care 2009, 32:394-396

15. Hayashi T, Farrell MA, Chaput LA, Rocha DA, Hernandez M: Lifestyle intervention, behavioral changes, and improvement in cardiovascular risk profiles in the California WISEWOMAN Project. J Womens Health (Larchmt) 2010, 19:1129-1138.

16. D'Agostino RB Sr, Grundy S, Sullivan LM, Wilson P, CHD Risk Prediction Group: Validation of the Framingham coronary heart disease prediction scores: results of a multiple ethnic groups investigation. JAMA 2001, 286:180-187.

17. Liu J, Hong Y, D'Agostino RB Sr, Wu Z, Wang W, Sun J, Wilson PW, Kannel WB, Zhao D: Predictive value for the Chinese population of the Framingham CHD risk assessment tool compared with the Chinese multi-provincial cohort study. JAMA 2004, 291:2591-2599.

18. Suka M, Sugimori $H$, Yoshida K: Application of the updated Framingham risk score to Japanese Men. Hypertens Res 2001, 24:685-689.

19. Suka M, Sugimori H, Yoshida K: Validity of the Framingham risk model applied to Japanese Men. Methods Inf Med 2001, 41:213-215.

20. Haruyama Y, Muto T, Nakade M, Kobayashi E, Ishisaki K, Yamasaki A: Fifteenmonth lifestyle intervention program to improve cardiovascular risk factors in a community population in Japan. Tohoku J Exp Med 2009, 217:259-269.

21. Fujii H, Muto T, Haruyama $Y$, Nakade M, Kobayashi E, Ishisaki K, Yamasaki A: Community-based lifestyle modification of cardiovascular disease risks in middle-aged Japanese: a 27-month update. Tohoku J Exp Med 2010, 220:307-318.

22. Okamoto E, Kaneita Y, Kobashi G, Sakada K, Sato T, Yoshiike N: Subnote Medical care and Public Health 2012. Tokyo: MEDELIKKUMEDELIA Cop; 2011 (in Japanese)

23. Seino $Y$, Nanjo K, Tajima N, Kadowaki T, Kashiwagi A, Araki E, Ito C, Inagaki N, Iwamoto Y, Kasuga M, Hanafusa T, Haneda M, Ueki K: Report of the committee on the classification and diagnostic criteria of diabetes mellitus (revision for international harmonization of $\mathrm{HbA} 1 \mathrm{c}$ in Japan). J Japan DiabSoc 2012, 55:485-514. in Japanese.

24. Friedewald WT, Levy RI, Fredrickson DS: Estimation of the concentration of low-density lipoprotein cholesterol in plasma, without use of the preparative ultracentrifuge. Clin Chem 1972, 18:499-502.

25. Lindström J, llanne-Parikka P, Peltonen M, Aunola S, Eriksson JG, Hemiö K, Hämäläinen $H$, Härkönen $P$, Keinänen-Kiukaanniemi S, Laakso M, Louheranta A, Mannelin M, Paturi M, Sundvall J, Valle TT, Uusitupa M, Tuomilehto J, Finnish Diabetes Prevention Study Group: Sustained reduction in the incidence of type 2 diabetes by lifestyle intervention: follow-up of the Finnish Diabetes Prevention Study. Lancet 2006, 368:1673-1679.

26. Elmer PJ, Obarzanek E, Vollmer WM, Simons-Morton D, Stevens VJ, Young DR, Lin PH, Champagne C, Harsha DW, Svetkey LP, Ard J, Brantley PJ, Proschan MA, Erlinger TP, Appel LJ, PREMIER Collaborative Research Group: Effects of comprehensive lifestyle modification on diet, weight, physical fitness, and blood pressure control: 18-month results of a randomized trial. Ann Intern Med 2006, 144:485-495.

27. Look AHEAD Research Group, Wing RR: Long-term effects of a lifestyle intervention on weight and cardiovascular risk factors in individuals with type 2 diabetes mellitus. Arch Intern Med 2010, 170:1566-1575.

28. Vadheim LM, Brewer KA, Kassner DR, Vanderwood KK, Hall TO, Butcher MK, Helgerson SD, Harwell TS: Effectiveness of a lifestyle intervention program among persons at high risk for cardiovascular disease and diabetes in a rural community. J Rural Health 2010, 26:266-272.

29. Lindström J, Louheranta A, Mannelin M, Rastas M, Salminen V, Eriksson J, Uusitupa M, Tuomileht J, Finnish Diabetes Prevention Study Group: The Finnish diabetes prevention study (DPS): lifestyle intervention and 3-year results on diet and physical activity. Diabetes Care 2003, 26:3230-3236.

doi:10.1186/1471-2458-13-219

Cite this article as: Zhu et al:: Evaluation of a community intervention program in Japan using Framingham risk score and estimated 10-year coronary heart disease risk as outcome variables: a non-randomized controlled trial. BMC Public Health 2013 13:219.

\section{Submit your next manuscript to BioMed Central and take full advantage of:}

- Convenient online submission

- Thorough peer review

- No space constraints or color figure charges

- Immediate publication on acceptance

- Inclusion in PubMed, CAS, Scopus and Google Scholar

- Research which is freely available for redistribution 